\title{
Evaluation of spatial memory and anti-fatigue function of long-term supplementation of $\beta$-alanine and confirmation through cAMP-PKA and apoptosis pathways in mice
}

\author{
Yi-Long Ma ${ }^{1,2}$, Yang Yang ${ }^{1}$, Kiran Thakur ${ }^{1,2}$, Carlos L. Cespedes-Acuña ${ }^{3}$, Jian-Guo Zhang ${ }^{1,2}$, Zhao-Jun Wei ${ }^{1,2, *}$ \\ ${ }^{1}$ Collaborative Innovation Center for Food Production and Safety, School of Biological Science and Engineering, North Minzu University, \\ Yinchuan 750021, China \\ ${ }^{2}$ School of Food and Biological Engineering, Hefei University of Technology, Hefei 230009, China \\ ${ }^{3}$ Department of Basic Sciences, Research Group in Chemistry and Biotechnology of Bioactive Natural Products, Faculty of Sciences, University \\ of Bio-Bío, Andrés Bello Avenue, Chillan, Chile
}

\section{ARTICLE INFO \\ Article History \\ Received 2 November 2021 \\ Accepted 1 December 2021 \\ Keywords \\ Betaalanine \\ Spatial memory \\ Fatigue resistance \\ Biochemical parameters \\ Oxidative stress \\ cAMPPKA and apoptotic pathway 2}

\begin{abstract}
A B S T R A C T
With an aim to explore the effects of $\beta$-alanine $(\beta-\mathrm{A})$ on spatial memory and fatigue resistance, Kunming mice were treated with different concentrations of $\beta$-A $\left(418,836\right.$, and $\left.2090 \mathrm{mg} \cdot \mathrm{kg}^{-1} \cdot \mathrm{day}^{-1}\right)$. After gavage feeding with $\beta$-A for 10 weeks, results of the maze and MWM tests showed that $\beta$-A can enhance spatial learning and memory in mice. After evaluating the fatigue resistance, biochemical parameters (LG, GG, BUN, SOD, and MDA) showed significant differences in the low concentration treatment group compared to control group. Our data demonstrated that the appropriate dose of $\beta$-A can alleviate the oxidative stress and muscle fatigue in mice. Subsequently, expression of mRNA of key genes involved in cAMP-PKA pathway (PDE4A, MAPK1, adcy1, cAMP and CREB) was up regulated. Also, expression levels of apoptotic pathway genes were significantly affected as confirmed by qPCR and Western blotting. Our results demonstrated that $\beta$-A can enhance spatial learning and memory in mice via regulation of cAMP-PKA and apoptotic pathway.
\end{abstract}

(C) 2021 The Authors. Publishing services by Visagaa Publishing House This is an open access article distributed under the CC BY-NC 4.0 license (https://creativecommons.org/licenses/by/4.0/).

\section{INTRODUCTION}

Beta-alanine $(\beta-\mathrm{A})$ as a non-essential amino acid (AA) in synergism with L-histidine synthesizes carnosine in vivo [1] and the latter is a dipeptide which is abundant in skeletal muscle. $\beta$ $\mathrm{A}$ is considered to be the rate-limiting precursor for carnosine production in vivo [2]. The exogenous supplementation with $\beta$ $A$ is considered to be an effective method for improvement of carnosine content in muscle [2]. $\beta$-A in the human body is mainly derived from food, and it is obtained mainly from fish and meat [3]. Supplementation with $\beta$-A has been shown to influence cycle capacity [4], ventilatory threshold, and fatigue time in humans [5]. However, with the supplementation higher than $800 \mathrm{mg}$, it can cause abnormalities in the host body [6]. Therefore, it is essential to select the appropriate dose for $\beta$-A supplementation to impart desired benefits.

Fatigue can be divided into muscle fatigue and nerve fatigue, which are caused by different conditions [7]. Recovering from fatigue state to normal state is a long process [8], which has a negative impact on the normal process of human body [9]. Muscle fatigue is closely related to the exercise intensity of body and it is often measured by metabolites produced during exercise [10]. During vigorous exercise, the occurrence of muscle fatigue is related to many factors.
The accumulation of acid in the muscle is considered to be one of the causes of fatigue. Carnosine has been shown to play an important role in regulating muscle $\mathrm{pH}$ [11]. Studies have shown that carnosine has a significant inhibitory effect on lipid oxidation caused by free radicals and metal ions [12], which promotes the release of calcium ions in skeletal muscle [13]. Brain is the most developed nerve organ in the human body. Normally, nerve fatigue is caused by excessive use of the brain. Insufficient sleep, long-term stress or anxiety can also lead to nerve fatigue, resulting into reduced efficiency [7].

In addition, studies have shown that several AA ( $\beta$-A, tryptophan, tyrosine, and arginine) were involved in spatial memory (cognition and memory) $[14,15]$. One study found that $\beta$-A may be involved in the early and late stages of spatial memory recovery in rats [15], while another study stated its non-significant effects for cognitive or muscle function in aged mice [16]. Therefore, involvement of $\beta$ - $A$ in the spatial memory and muscle function still remains unclear. The aim of the present study was to investigate the ability of mice to resist fatigue and improve the spatial memory after supplementation with different concentrations of $\beta$-A (low, medium, and high). Further, we evaluated the possible correlation between these two functions in mice. Subsequently, we also evaluated the expression of key genes and proteins related to apoptosis and cAMP-PKA signaling pathways.

${ }^{\star}$ Corresponding author. Emails: zjwei@hfut.edu.cn

Peer review under responsibility of the International Association of Dietetic Nutrition and Safety 


\section{MATERIALS AND METHODS}

\subsection{Animals}

Male Kunming mice ( 4 weeks old, $\mathrm{N}=48$ ) were purchased from Changzhou Cavens Experimental Animal Co., Ltd [production license number: $\operatorname{SCXK}(\mathrm{Su}, 2016-0010)]$. The mice were housed in a constant temperature $\left(24^{\circ} \mathrm{C}\right)$ under ventilated environment. Mice were housed under a reverse $12 \mathrm{~h}$ light-dark cycle, (light cycle started at 7:00am, and dark cycle started at 7:00 pm). Mice were acclimatized for five days before gavage feeding with different doses of $\beta$-A. All the animal procedures were performed in accordance with the National Institutes of Health Laboratory Animal Care and Use Guidelines. Our experiment plan was approved by the Institutional Animal Care and Use Committee of Hefei University of Technology, China.

\subsection{Diets}

$\beta$-A was purchased from Shanghai Macklin Biochemical Co., Ltd (CAS:107-95-9; Shanghai, China). All the mice were given a standard chow diet and water ad libitum. Initially, 48 mice were divided into 4 groups comprised of 12 animals in each group. The control group was given a normal saline instead of $\beta$-A. The dose of $\beta$-A in the low concentration group was $418 \mathrm{mg} \cdot \mathrm{kg}^{-1} \cdot \mathrm{day}^{-1}$, the medium concentration group was $836 \mathrm{mg} \cdot \mathrm{kg}^{-1} \cdot \mathrm{day}^{-1}$, and the high concentration group was $2090 \mathrm{mg} \cdot \mathrm{kg}^{-1} \cdot \mathrm{day}^{-1}[16,17]$. Regular gavage feeding was performed at AM9 at a dose of $200 \mathrm{ml}$ daily which lasted for 10 weeks.

\subsection{Experimental design}

The experimental design was shown in Figure 1A. The mice were gavage fed with $\beta$-A for 10 weeks. The $\mathrm{y}$-maze experiment was performed on the $1^{\text {st }}$ day and the $2^{\text {nd }}$ day after 10 weeks of gavage feeding. The Morris water maze (MWM) test was performed from the $3^{r d}$ day to the $7^{t h}$ day. On the $8^{t h}$ day, the mice were trained to swim for five minutes, followed by immediate euthanization with $\mathrm{CO}_{2}$ asphyxiation. On the $8^{\text {th }}$ day of feeding, for the behavioral test, mice were euthanized, and blood samples, liver, gastrocnemius, and hippocampus were collected immediately and stored at $-80^{\circ} \mathrm{C}$ for cryopreservation.

\subsection{Y-maze test}

For this test, previously described procedure was followed [18]. Briefly, y-maze was procured from ShangHai XinRuan Information Technology Co., Ltd. consisted of three identical arms made up of organic plates, with black adhesive tape on the inner and outer walls, each with an angle of 120 degree. Each arm had a size of $30 \mathrm{~cm} \times$ $8 \mathrm{~cm} \times 15 \mathrm{~cm}$ (length $\times$ width $\times$ height). There was a movable partition at the center, and different geometric figures were attached to each arm of the labyrinth as visual markers [18]. The camera was installed above the maze to record the whole process. The three arms of the Y maze were randomly set to start arm, novel arm, and family arm. Novel arm was blocked by a partition during the
$\mathbf{A}$

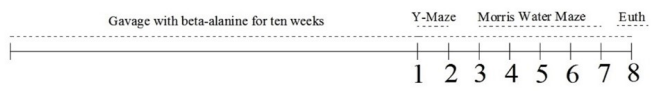

B

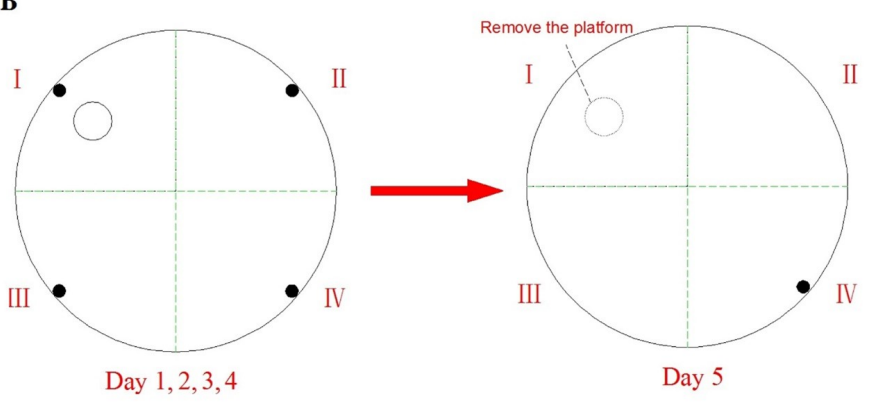

Figure 1 Experimental design forEuth (A): swimming, euthanasia, and tissue collection. MWM experimental detail(B). Black dots indicate the mice entry point. The dotted lines indicate thedividing of pool into four parts.

first phase of the experiment, during the training period, and it was opened during the second phase of the test. The mouse entered at the start arm where the maze was located. From the end of the arm, the mouse head was placed towards the arm. The start arm and the family arm were always kept open throughout the experiment.

The experiment consisted of two steps for each mouse, with the first step which lasted for 10 minutes followed by two hours, the next step lasted for five minutes. The first step was to close the novel arm and let each mouse explore for free for 10 minutes inside the other two arms. After two hours, while proceeding to the second step, all the arms were opened and each mouse was allowed to explore for five minutes inside three arms. At the end of each experiment, alcohol was used to remove the odor from the maze to prevent interference. The final parameters to be studied were the number of times the mouse entered in each arm, and the time and distance of exploration in each arm [19].

\subsection{Morris water maze test}

The MWM was procured from ShangHai XinRuan Information Technology Co., Ltd. The MWM consisted of a circular pool with a diameter of $1.2 \mathrm{~m}$ and a height of $0.45 \mathrm{~m}$. Briefly, mice were allowed to swim in order to find the platform hidden under the water surface ( $1 \mathrm{~cm}$ below water). A camera tracking system was installed above the pool to record the whole process. The caramel color was added to the water for turning the water into black liquid, which is convenient for the system to follow. The temperature of water was controlled at $20 \pm 2{ }^{\circ} \mathrm{C}$, and the maze was divided into four quadrants. Each quadrant was marked with a different marker in the wall of the pool for observation as described previously [20]. The MWM test was started at 10 am and completed at $4 \mathrm{pm}$ on the daily basis. The whole experiment was carried out without light exposure to prevent the visual interference of light on mice [21].

The MWM test can be divided into two parts: Concealed platform test: At the first four days of the MWM experiment, each mouse was placed in the four different quadrants (I, II, III, IV) facing the pool wall (Figure 1B). Mice were trained four times a day and each 
quadrant were used only once a day. The platform was placed in the I quadrant and each mouse was allowed to swim for 60 seconds to find a hidden platform. If the platform was successfully found, the mouse can rest on the platform for 10 seconds. On the contrary, if the platform was not found, mouse was manually placed on the platform and allowed to rest for 10 seconds. Occasionally, mice may jump into the water from the platform to continue swimming. In that case, the mouse was put back on the platform and allowed to rest for 10 seconds. The above step ensured that each mouse had equal time to observe and acquire spatial information after each experiment [22].

Space exploration test: After the end of the hidden platform test, the platform was removed on the $5^{t h}$ day. The mice were placed in water at the opposite side of the original platform position [23]. The swimming paths of mice within 60 seconds were recorded. The time of the mice stay in the original platform (I) quadrant was also recorded as shown in Figure 1B.

At the end of the MWM test, the final parameters to be given include the average speed, the total distance of swimming, and the time required to reach the platform of each mouse every day. If the mouse did not find the hidden platform within the prescribed time (60 seconds), it was moved to platform. The time of mice staying in the original platform (I) quadrant on the last day of the test was also recorded.

\subsection{Quantitative real-time polymerase chain reaction (qPCR}

For this, the hippocampus, a complex brain part of mice was grinded into powdered form in liquid nitrogen followed by mixing with $1 \mathrm{ml}$ RNA isolater for lysis. Then, total RNA was extracted using HiScript Q RT SuperMix kit (Nanjing Vazyme Biotech Co., Ltd.). The purity of RNA was determined by A260/A280. Reverse transcription was performed using a PrimeScript RT kit (Nanjing Vazyme Biotech Co., Ltd. Nanjing, China) according to the manufacturer's instructions. qPCR was performed using SYBR Green Pro Taq HS DimerEraser (Accurate Biotechnology Co., Ltd; Beijing, China) with a Fast-RealTime PCR System [24]. The qPCR conditions were as follow: heating to $95^{\circ} \mathrm{C}$ for $30 \mathrm{~s}$, followed by 40 cycles at $95^{\circ} \mathrm{C}$ for $5 \mathrm{~s}, 60^{\circ} \mathrm{C}$ for 30 $\mathrm{s}$ [25]. Each sample was tested with at least in independent triplicates to check the data reproducibility.

\subsection{Western blot analysis}

Hippocampal tissues were collected with RIPA lysis buffer (containing 1\% PMSF protease inhibitors) to isolate proteins. Protein concentrations were determined using a Bradford Protein Assay Kit (Bio-Rad, Hercules, CA, USA) [26]. Associated proteins were detected using primary antibodies specific for beta-actin, Bcl-2, Bax, Caspase-9, and Caspase-3. The diluted corresponding secondary antibody was added and incubated at room temperature for $1 \mathrm{~h}$. Finally, membrane was washed with TBST for three times, and the protein expression was detected by ECL luminescence method [27].

\subsection{Determination of biochemical parameters}

In anti-fatigue activity experiments. after final administration on $8^{\text {th }}$ day, the mice were allowed to swim for five minutes inside the pool followed by immediate euthanization using $\mathrm{CO}_{2}$ asphyxiation. Blood samples were collected by cardiac blood sampling, and centrifuged at $5000 \mathrm{rpm}$ for 10 minutes at low temperature conditions. After centrifugation, the supernatant was taken for the determination of blood urea nitrogen (BUN) and lactic acid (LA) and placed in $-80^{\circ} \mathrm{C}$. Consequently, liver, gastrocnemius, and brain hippocampus tissues were placed in $-80{ }^{\circ} \mathrm{C}$ for the determination of liver glycogen (LG), gastrocnemius glycogen (GG), LA and biochemical parameters related to antioxidant activity.

\subsection{Statistical analysis}

All data were expressed as mean \pm SD. The data were analyzed by One-way ANOVA through SPSS Statistics 20.0 (SPSS, Inc., Chicago, IL, USA) followed by DunCan's multiple comparison test with $\mathrm{p}<$ 0.05 of significance.

\section{RESULTS AND DISCUSSION}

\subsection{Y-maze test}

Since any changes in physical activity may affect the results of $y$ maze test, therefore, the exploratory behavior of all experimental mice was evaluated. As shown in Figure 2, the significant differences were observed for the distance travelled, mean speed, and number of line crossings in the low and medium concentration groups compared with the control group. The total distance traveled (Figure 2A) was longer, the mean speed (Figure 2B) was faster, and the number of line crossings (Figure $2 \mathrm{C}$ ) was more $(\mathrm{p}<0.01)$ compared to control group.

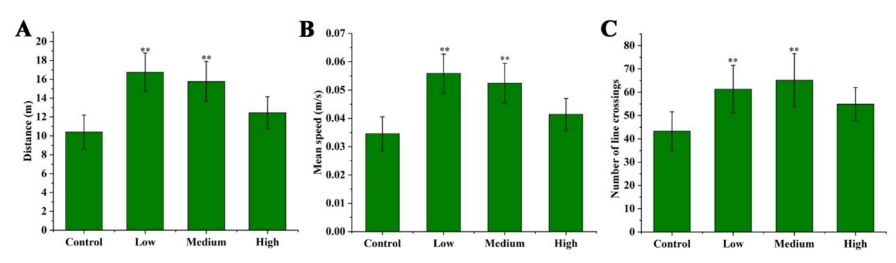

Figure 2 Movementparameters of different groups of mice. Data for the total distance travelled (A),the mean speed (B), and the number of line crossings $(\mathrm{C})$ are shown. The dose of $\beta$-A in the low concentration groupwas $418 \mathrm{mg} \cdot \mathrm{kg}^{-1} \cdot \mathrm{day}^{-1}$, the medium concentration groupwas $836 \mathrm{mg} \cdot \mathrm{kg}^{-1} \cdot \mathrm{day}^{-1}$, and the high concentration groupwas 2090 $\mathrm{mg} \cdot \mathrm{kg}^{-1} \cdot \mathrm{day}^{-1}$. The difference between thecontrol and dose groups were analyzed by one-way ANOVA followed by DunCan's multiple comparison test with $\mathrm{p}<0.01$ of significancerepresented by ${ }^{* *}$.

The y-maze test was analyzed from two different perspectives: (1) The percentage of total test time spent by mice in each of the four areas of the maze was calculated (Figure 3A). (2) The discrimination index of $y$-maze data was analyzed, and the preferences of mice for familiar and novel arm were compared (Figure 3B). The 
observations for spatial memory tests are shown in Figure 3. The control group showed a characteristic feature with a preference to move in the start arm which accounted for $58 \%$ of the total time. The control group mice only moved in the start arm, while there was no such phenomenon in the other three groups. This suggests that $\beta$-A may improve the exploratory behavior of mice. In the novel arm, there was a significant difference between the dose groups and the control group (Figure 3A; $\mathrm{p}<0.05$ ). Low concentration of $\beta$ A accounted for $35.85 \%$ and medium concentration accounted for $31.63 \%$ of the total time, while the control group only accounted for $17.25 \%$ of the total time. The low and medium concentration groups spent more time exploring in the novel arm than any other arms. Compared with the familiar arm, mice preferred to explore in the novel arm (Figure 3B). The data indicated that administration of a suitable dose of $\beta$-A to mice may have a positive effect on its short-term spatial memory.
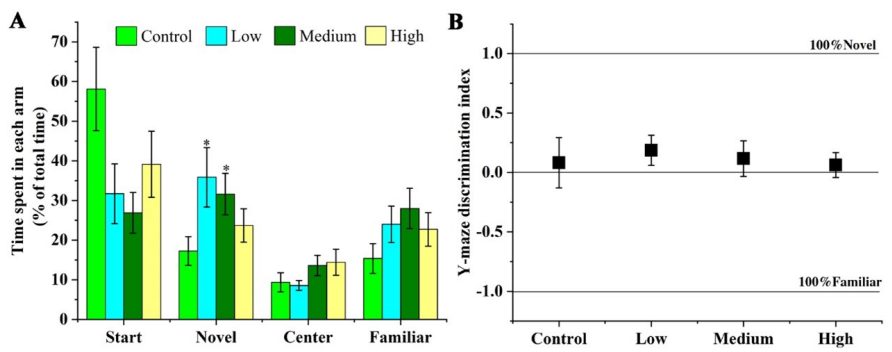

Figure 3 Y-mazetest. (A) The ordinate was expressed as the percentage of time spent by mice oneach arm of the total time (300 seconds). The data were significantly differentin the novel arm with $\mathrm{p}<0.05$ of significance represented by ${ }^{*}$. (B)Discrimination index is comparison between the time of mice exploring in familiararm and novel arm. If the value approached 1.0, it means that mice preferred toexplore in the novel arm. When the value approached -1.0 , mice preferred toexplore in the familiar arm. The dose of $\beta$-Ain the low concentration group was $418 \mathrm{mg} \cdot \mathrm{kg}^{-1} \cdot \mathrm{day}^{-1}$, themedium concentration group was $836 \mathrm{mg} \cdot \mathrm{kg}^{-1} \cdot \mathrm{day}^{-1}$, andthe high concentration group was 2090 $\mathrm{mg} \cdot \mathrm{kg}^{-1} \cdot \mathrm{day}^{-1}$.

\subsection{Morris water maze test}

From the $1^{\text {st }}$ day to the $4^{\text {th }}$ day of the MWM experiment, the time taken by all the mice to reach the platform was shortened (Figure $4 \mathrm{~A}, 4 \mathrm{~B} ; \mathrm{p}<0.01$ ) indicating that mice had a memory of the platform. Although the speed was observed to be faster with the increase in number of days, but it was non-significant. From the results (Figure 4C), it can be seen that when the mice were allowed to swim, the instantaneous speed of mice slowed down with the increase in swimming time.

While analyzing individually, there was no significant difference observed in the time taken by different groups of mice to reach the platform (Figure 5A). The change in the time taken by the low concentration group was maximum, from the slowest on the $1^{\text {st }}$ day to the fastest on the $4^{t h}$ day. In the space exploration test (Figure $5 \mathrm{~B})$, it is reported that the longer the mice stayed in the platform (I) quadrant, it resulted into better spatial memory. As shown in Figure 5B, the control and low concentration groups were observed for taking slightly more time as compared to other two groups.
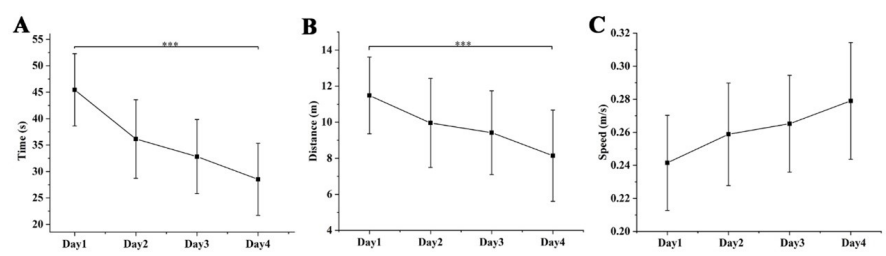

Figure 4 Concealed platform test. Time to reach the platform (A), total swimming distance to reach the platform (B), and average speed (C). Data were analyzed with one-way ANOVA followed by DunCan's multiple comparison test with $\mathrm{p}<0.001$ represented by ${ }^{* * *}$.

However, there was no significant difference observed between the four groups ( $p>0.05$ ). To conclude, the results of MWM and $y-$ maze experiments were consistent with previous study [15] Previous reports suggest that $\beta$-A and citrulline may be involved in early and late phases of spatial memory retrieval in the rat. To summarize, $\beta$ A may improve spatial memory ability of mice, but the conclusions are still open [28].
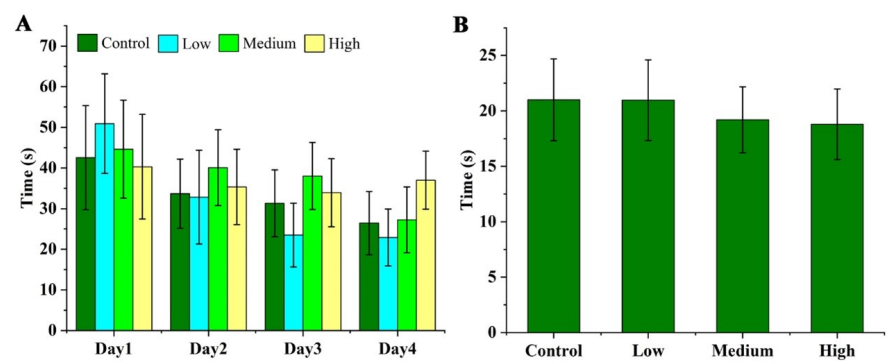

Figure 5 MWM test. (A) Time taken by different groups of mice to reach the platform. (B)Space exploration test. The time of mice stay in the original platform (I)quadrant. The dose of $\beta$ $\mathrm{A}$ in the low concentration group was $418 \mathrm{mg} \cdot \mathrm{kg}^{-1} \cdot \mathrm{day}^{-1}$, the medium concentration group was $836 \mathrm{mg} \cdot \mathrm{kg}^{-1} \cdot \mathrm{day}^{-1}$, and the high concentration group was $2090 \mathrm{mg} \cdot \mathrm{kg}^{-1} \cdot \mathrm{day}^{-1}$.

\subsection{Evaluation of the toxicity of supplementation of $\beta$-A to mice}

The hematological parameters in mice administered with $\beta$-A for 10 weeks were investigated (Table 1 ). Hematological parameters results showed that there were no significant differences $(p>0.05)$ between the mice fed with $\beta$-A and control group. The indicators of hematological parameters of mice fed with $\beta$-A are all within the normal range (Table 1 ). The above results demonstrated that long term supplementation of $\beta$-A displayed no toxicity to mice.

\subsection{Determination of fatigue biochemical parameters}

The degree of fatigue can normally be judged by their individual feelings and several biochemical indicators. Low-molecular lactose and other low molecular compounds can produce glycogen in liver or muscle, which is a major process of energy storage. Energy can be produced by the decomposition of glycogen [29]. Glycogen can 
Table 1 Hematological parameters in mice administered with $\beta$-A for 10 weeks.

\begin{tabular}{lllllll}
\hline Parameter & Control & Low & Middle & High & Unit & Reference range \\
WBC & $4.2 \pm 0.54$ & $3.3 \pm 0.52$ & $3.8 \pm 0.57$ & $3.1 \pm 0.43$ & $10^{9} / \mathrm{L}$ & $0.8-6.8$ \\
Lymph & $3.4 \pm 0.40$ & $3.1 \pm 0.43$ & $4.2 \pm 0.67$ & $3.8 \pm 0.48$ & $10^{9} / \mathrm{L}$ & $0.7-5.7$ \\
Mon & $0.23 \pm 0.034$ & $0.25 \pm 0.032$ & $0.19 \pm 0.026$ & $0.20 \pm 0.024$ & $10^{9} / \mathrm{L}$ & $0.0-0.3$ \\
Gran & $0.6 \pm 0.09$ & $0.9 \pm 0.10$ & $0.7 \pm 0.09$ & $1.1 \pm 0.16$ & $10^{9} / \mathrm{L}$ & $0.1-1.8$ \\
Lymph & $82 \pm 11.48$ & $73.2 \pm 10.98$ & $70.8 \pm 8.49$ & $74.1 \pm 12.59$ & $\%$ & $55.8-90.6$ \\
Mon & $3.7 \pm 0.48$ & $2.3 \pm 0.39$ & $5.1 \pm 0.76$ & $3.9 \pm 0.50$ & $\%$ & $1.8-6.0$ \\
Gran & $14.3 \pm 1.71$ & $14.5 \pm 1.88$ & $14.1 \pm 2.39$ & $22 \pm 2.86$ & $\%$ & $8.6-38.9$ \\
RBC & $7.96 \pm 1.19$ & $8.75 \pm 1.13$ & $7.61 \pm 0.98$ & $4.24 \pm 0.50$ & $10^{12} / \mathrm{L}$ & $6.36-9.42$ \\
HGB & $127 \pm 21.5$ & $119 \pm 14.2$ & $122 \pm 15.8$ & $103 \pm 15.4$ & $\mathrm{~g} / 1$ & $110-143$ \\
HCT & $37.5 \pm 4.87$ & $39.2 \pm 5.80$ & $34.9 \pm 4.18$ & $29.2 \pm 4.67$ & $\%$ & $34.6-44.6$ \\
MCV & $46.8 \pm 6.08$ & $48.4 \pm 8.22$ & $43.2 \pm 6.48$ & $44.9 \pm 6.28$ & $\mathrm{fl}$ & $40.2-50.3$ \\
MCH & $16.6 \pm 1.99$ & $16.6 \pm 2.15$ & $16.4 \pm 2.62$ & $16.8 \pm 2.18$ & $\mathrm{pg}$ & $15.8-19$ \\
MCHC & $312 \pm 46.8$ & $309 \pm 40.1$ & $311 \pm 43.5$ & $285 \pm 34.2$ & $\mathrm{~g} / 1$ & $302-353$ \\
RDW & $16.0 \pm 2.56$ & $15.1 \pm 1.81$ & $14.9 \pm 1.93$ & $16.7 \pm 2.50$ & $\%$ & $13-17$ \\
PLT & $873 \pm 122$ & $847 \pm 131$ & $679 \pm 81$ & $717 \pm 131$ & $10^{9} / \mathrm{L}$ & $450-1590$ \\
MPV & $5.6 \pm 0.72$ & $5.4 \pm 0.86$ & $5.1 \pm 0.76$ & $6.6 \pm 0.85$ & $\mathrm{fl}$ & $3.8-6.0$ \\
\hline
\end{tabular}

supplement the consumption of blood sugar during exercise and maintain normal levels. Therefore, the content of glycogen can indicate the anti-fatigue ability of body [30]. As shown in Figure 6A and $6 \mathrm{~B}$, the content of $\mathrm{LG}$ and MG in low concentration group was higher $(25.72 \%$ and $21.28 \%)$ than that in control group ( $p>0.05)$. Glycolysis is the main route for energy supply during short-term intense exercise. The content of LA in plasma and liver represents the degree of fatigue and recovery after exercise [31]. There was no significant difference in LA content among the four groups (Figure $6 \mathrm{C}, 6 \mathrm{D})$. The average values of each group were similar which may be due to the fact that mice were killed after swimming for five minutes and could not exercise intensely during the swimming. Because only under intense exercise, a large amount of LA can be produced.

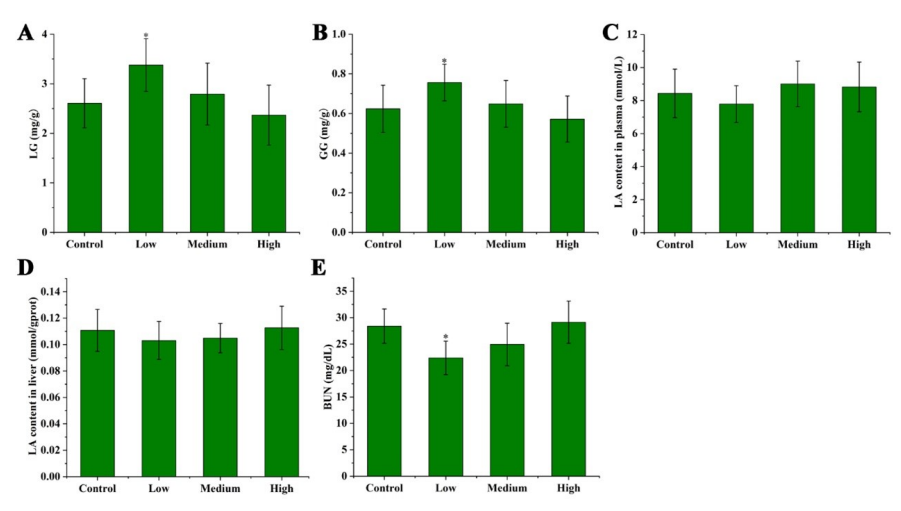

Figure 6 AfterExercise, effectsof beta-alanine on LG (A) and GG (B). LA content in plasma (C) and liver (D). Effectsof beta-alanine on BUN (E). p $<0.05$ ofsignificance was represented by *. The dose of $\beta$-A in the low concentration group was $418 \mathrm{mg} \cdot \mathrm{kg}^{-1} \cdot \mathrm{day}^{-1}$, the medium concentration group was $836 \mathrm{mg} \cdot \mathrm{kg}^{-1} \cdot \mathrm{day}^{-1}$, and the high concentration group was $2090 \mathrm{mg} \cdot \mathrm{kg}^{-1} \cdot \mathrm{day}^{-1}$.

Urea nitrogen is the main end product of human protein metabolism. The amount of BUN is also an indicator of body fatigue [32]. The BUN content in the low concentration group was significantly lesser than that in the control group $(\mathrm{p}<0.05)$. The content of the high concentration group was more than that of the control group (Figure 6E).

The oxidative stress caused by exercise fatigue can produce reactive oxygen species. If the gavage fed mice with $\beta$-A possess antioxidant attribute, it can indirectly reflect the anti-fatigue ability of the mice [33]. For the anti-oxidant assay, tissues from two different parts (liver and hippocampus) were measured. In the liver, there were significant differences in SOD and MDA between the low concentration group and the control group (Figure $7 \mathrm{~A} ; \mathrm{p}<0.05$ ). $\mathrm{SOD}$ in low concentration group was higher than that in control group and MDA in control group was higher than that in low concentration group. MDA is usually measured together with SOD. SOD activity reflects the ability of body to eliminate oxygen free radicals. MDA content reflects the severity of free radical attack on muscle cells. Our results can clearly reflect the antioxidant capacity of mice fed with $\beta$-A. This suggests that the mice in the low concentration group may have antioxidant capacity in vivo. In this way, $\beta$-A may have indirect beneficial role in delaying the muscle fatigue. No significant difference between the other three groups was observed which demonstrates that the dosage of $\beta$-A is the key criteria. Furthermore, there was no significant difference observed in GSH-PX activity between all the four groups (Figure 7B). This may be due to the fact GSH-PX can only promote the reaction between $\mathrm{H}_{2} \mathrm{O}_{2}$ and $\mathrm{GSH}$ to produce $\mathrm{H}_{2} \mathrm{O}$ and GSSG and latter two can also react without GSH-PX. Therefore, compared with the direct action of SOD on free radicals, GSH-PX only plays a catalytic role which is not rational to completely explain the antioxidant capacity in vivo. In the hippocampus, there was no significant difference in the three biochemical parameters (GSH-PX, MDA, SOD) between the three groups (Figure 7C and 7D). However, experimental group (low concentration) and the control group showed non- significant difference which may be due to individual data dissimilarities, resulting in less obvious results. To summarize, $\beta$-A can alleviate oxidative stress in the liver and play an anti-fatigue role in mice. The anti-fatigue test results of $\beta$-A were similar to previously [34]. It can be concluded that $\beta$-A can improve endurance performance and delay the onset of muscle fatigue. 

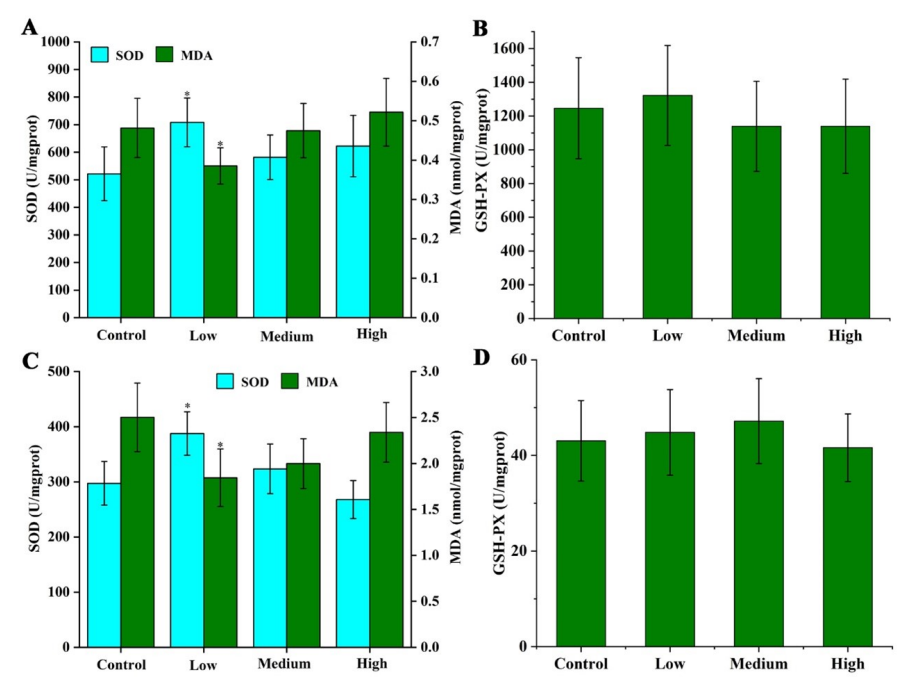

Figure 7 Effectof beta-alanine on GSH-PX, SOD activities and MDA content in liver of mice (Aand B). Effect of beta-alanine on GSHPX, SOD activities, and MDA content inhippocampus of mice (C and $\mathrm{D}) . \mathrm{p}<0.05$ of significancewas represented by ${ }^{*}$. The dose of $\beta$-Ain the low concentration group was $418 \mathrm{mg} \cdot \mathrm{kg}^{-1} \cdot \mathrm{day}^{-1}$, the medium concentration group was $836 \mathrm{mg} \cdot \mathrm{kg}^{-1} \cdot \mathrm{day}^{-1}$, and the high concentration group was $2090 \mathrm{mg} \cdot \mathrm{kg}^{-1} \cdot \mathrm{day}^{-1}$.

\section{5. $B$-A inhibits neuroinflammation and improves memory behavior in mouse}

As shown in Figure 8, according to the physiological processes involved in genes, we divided the 15 target genes into two categories. The first type was related to inflammation, apoptosis, and synaptic plasticity. We found that the expression levels of some apoptosisrelated genes and pro-inflammatory factors (such as bcl2, caspase3, IL4, IL6, and BDNF) were significantly reduced after $\beta$-A treatment $(\mathrm{P}<0.01)$. In addition, we found that $\beta$-A had a significant role for inhibiting the inflammatory process and regulating the apoptosis process. The second type was related to cAMP-PKA signaling pathway. We found that the expression trends of PDE4A, MAPK1, adcyl, and cAMP response element binding protein (CREB) genes were similar with up regulation, with the most pronounced results at medium concentrations $(\mathrm{p}<0.01)$.

The PKA signaling pathway is important for memory, and the effect of the PKA signaling pathway promotes hippocampal-dependent memory. Studies have shown that antioxidant stress kinases / molecules $(\mathrm{GPx}$, catalase, $\mathrm{SOD}$, etc.) play an essential role in learning and spatial memory. Furthermore, oxidative stress can trigger the apoptosis process. The mRNA expression data revealed that $\beta$-A has significant role in inhibiting the inflammatory process and regulating the apoptosis process which was in accordance with the results of previous study where $\beta$-A improved the expression of memory related genes in mice [15].

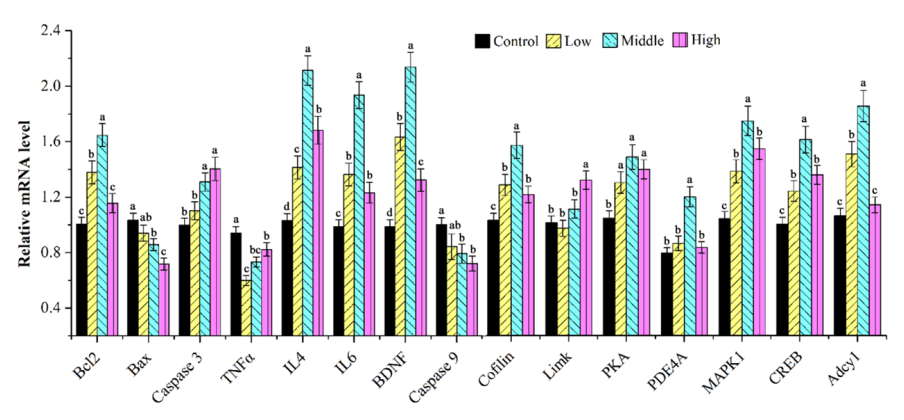

Figure 8 MRNAlevels of genes involved in apoptosis and cAMP-PKA pathways. Compared with thecontrol group, a, b, c, and d represent the significant differences $\mathrm{p}<0.05$. The dose of $\beta$-A in thelow concentration group was $418 \mathrm{mg} \cdot \mathrm{kg}^{-1} \cdot \mathrm{day}^{-1}$, themedium concentration group was $836 \mathrm{mg} \cdot \mathrm{kg}^{-1} \cdot \mathrm{day}^{-1}$, andthe high concentration group was 2090 $\mathrm{mg} \cdot \mathrm{kg}^{-1} \cdot \mathrm{day}^{-1}$.

\section{6. $B$-A improves protein expression of apoptosis-related genes}

In this study, the expression of pro-apoptotic member Bak was significantly up-regulated, while the expression of anti-apoptotic Bcl-2 was decreased. As shown in Figure 9, after administration with $\beta$-A, the levels of mRNA and protein associated with apoptosis were significantly affected. As the $\beta$-A concentration increased, the levels of Caspase- 3 and Caspase- 9 proteins were down-regulated which was in similar trend to the results obtained in previous study [15].

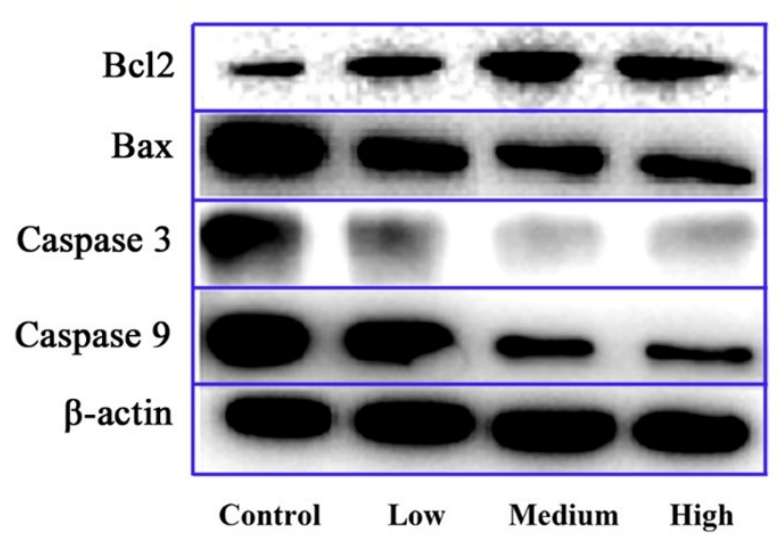

Figure 9 Theexpression levels of apoptosis-related genes and proteins in the hippocampus ofmice after treatment with increased concentrations of $\beta$-A (Control group, low group 418 $\mathrm{mg} \cdot \mathrm{kg}^{-1} \cdot \mathrm{day}^{-1}$, medium group $836 \mathrm{mg} \cdot \mathrm{kg}^{-1} \cdot \mathrm{day}^{-1}$, and high group $2090 \mathrm{mg} \cdot \mathrm{kg}^{-1} \cdot \mathrm{day}^{-1}$ ). The dose of $\beta$-A in the low concentration group was $418 \mathrm{mg} \cdot \mathrm{kg}^{-1} \cdot \mathrm{day}^{-1}$, the medium concentration group was $836 \mathrm{mg} \cdot \mathrm{kg}^{-1} \cdot \mathrm{day}^{-1}$, and the high concentration group was 2090 $\mathrm{mg} \cdot \mathrm{kg}^{-1} \cdot \mathrm{day}^{-1}$.

\section{CONCLUSIONS}

Through the $y$-maze test results, we speculate that intragastric administration with $\beta$-A may have a positive effect on short-term 
spatial memory in mice. From MWM data, no change in the long-term spatial memory of mice was noticed after intragastric administration with $\beta$-A. MWM test confirmed the role of $\beta$-A for improving the short-term spatial memory in mice. Appropriate dose of $\beta$-A improves the fatigue resistance of mice by alleviating oxidative stress in vivo. After $\beta$-A administration, the content of SOD and MDA changed significantly. Our results demonstrated that $\beta$-A may be involved in the regulation of the cAMPPKA pathway to improve the learning and memory. Medium concentration dose of $\beta$-A had a significant role for inhibiting the inflammatory process and regulating the apoptosis process and in the promotion of hippocampal-dependent memory. Taken together, these findings provide strong evidence that oxidative stress affects learning and memory.

\section{ETHICAL APPROVAL}

All procedures performed in studies involving animals were in accordance with the ethical standards of Hefei University of Technology.

\section{ABBREVIATIONS}

$\beta$-A, beta-alanine; AA, amino acid; MWM, Morris water maze; LG, liver glycogen; GG, gastrocnemius glycogen; LA, lactic acid; BUN, blood urea nitrogen; SOD, superoxide dismutase; MDA, malondialdehyde; GSH-PX, glutathione peroxidase.

\section{CONFLICTS OF INTEREST}

The authors declare that they have no conflict of interest.

\section{ACKNOWLEDGEMENTS}

This work was supported by the National Natural Science Foundation of Ningxia Province (2021AAC02019), the Youth talent cultivation project of North Minzu University (2021KYQD27, FWNX14), Key research and development projects in Ningxia (2021BEF02013).

\section{REFERENCES}

[1] Dunnett M, Harris RC. Influence of oral beta-alanine and L-histidine supplementation on the carnosine content of the gluteus medius. Equine Veterinary Journal. 1999;31(s30):499504. doi:10.1111/j.2042-3306.1999.tb05273.x.

[2] Harris RC, Tallon M, Dunnett M, Boobis L, Coakley J, Kim HJ, et al. The absorption of orally supplied beta-alanine and its effect on muscle carnosine synthesis in human vastus lateralis. Amino Acids. 2006;30(3):279-289. doi:10.1007/s00726-006-0299-9.

[3] Hoffman JR, Stout JR, Harris RC, Moran DS. $\beta$-Alanine supplementation and military performance. Amino Acids. 2015;47(12):2463-2474. doi:10.1007/s00726-015-2051-9.

[4] Hill CA, Harris RC, Kim HJ, Harris BD, Sale C, Boobis LH, et al. Influence of $\beta$-alanine supplementation on skeletal muscle carnosine concentrations and high intensity cycling capacity. Amino Acids. 2007;32(2):225-233. doi:10.1007/s00726-0060364-4.
[5] Stout JR, Cramer JT, Zoeller RF, Torok D, Costa P, Hoffman JR, et al. Effects of beta-alanine supplementation on the onset of neuromuscular fatigue and ventilatory threshold in women. Amino Acids. 2007;32:381-386. doi:10.1007/s00726-006-0474-z.

[6] Decombaz J, Beaumont M, Vuichoud J, Bouisset F, Stellingwerff T. Effect of slow-release beta-alanine tablets on absorption kinetics and paresthesia. Amino Acids. 2012;43(1):67-76. doi:10.1007/s00726-011-1169-7.

[7] Caldwell JA, Caldwell JL, Thompson LA, Lieberman HR. Fatigue and its management in the workplace. Neuroscience \& Biobehavioral Reviews. 2019;96:272-289. doi:10.1016/j.neubiorev.2018.10.024.

[8] Lee N, Lee SH, Yoo HR, Yoo HS. Anti-Fatigue Effects of Enzyme-Modified Ginseng Extract: A Randomized, Double-Blind, Placebo-Controlled Trial. The Journal of Alternative and Complementary Medicine. 2016;22(11):859-864. doi:10.1089/acm.2016.0057.

[9] Teng YS, Wu D. Anti-Fatigue Effect of Green Tea Polyphenols (-)Epigallocatechin-3-Gallate (EGCG). . Pharmacognosy Magazine. 2017;13:326-331. doi:10.4103/0973-1296.204546.

[10] Finsterer J. Biomarkers of peripheral muscle fatigue during exercise. BMC Musculoskeletal Disorders. 2012;13:218-218. doi:10.1186/1471-2474-13-218.

[11] Suzuki Y, Ito O, Mukai N, Takahashi H, Takamatsu K. High level of skeletal muscle carnosine contributes to the latter half of exercise performance during 30-s maximal cycle ergometer sprinting. The Japanese Journal of Physiology. 2002;52(2):199_ 205. doi:10.2170/jjphysiol.52.199.

[12] Chasovnikova LV, Formazyuk VE, Sergienko VI, Boldyrev AA, Severin SE. The antioxidative properties of carnosine and other drugs. Biochemistry international. 1990;20(6):1097-1103.

[13] Dutka TL, Lamboley CR, Mckenna MJ, Murphy RM, Lamb GD. Effects of carnosine on contractile apparatus $\mathrm{Ca} 2+$ sensitivity and sarcoplasmic reticulum $\mathrm{Ca} 2+$ release in human skeletal muscle fibers. Journal of Applied Physiology. 2012;112(5):728-736. doi:10.1152/japplphysiol.01331.2011.

[14] Hosseini M, Headari R, Oryan S, Hadjzadeh MA, Saffarzadeh F, Khazaei M. The effect of chronic administration of L-arginine on the learning and memory of estradiol-treated ovariectomized rats tested in the morris water maze. Clinics. 2010;65(8):803-807. doi:10.1590/s1807-59322020000800012.

[15] Sase A, Dahanayaka S, Höger H, Wu G, Lubec G. Changes of hippocampal beta-alanine and citrulline levels are paralleling early and late phase of retrieval in the Morris Water Maze. Behavioural Brain Research. 2013;249:104-108. doi:10.1016/j.bbr.2013.04.033.

[16] Pence BD, Bhattacharya TK, Park P, Rytych JL, Allen JM, Sun $\mathrm{Y}$, et al. Long-term supplementation with EGCG and betaalanine decreases mortality but does not affect cognitive or muscle function in aged mice. Experimental Gerontology. 2017;98:22-29. doi:10.1016/j.exger.2017.08.020.

[17] Stout JR, Graves BS, Smith AE, Hartman MJ, Cramer JT, Beck TW, et al. The effect of beta-alanine supplementation on neuromuscular fatigue in elderly (55-92 Years): a double-blind randomized study. Journal of the International Society of Sports Nutrition. 2008;5:21-21. doi:10.1186/1550-2783-5-21.

[18] Gde PC, Bortolotto JW, Blazina AR, Christoff RR, Lara DR, Vianna MR, et al. Y-Maze memory task in zebrafish (Danio rerio): The role of glutamatergic and cholinergic systems on the acquisition and consolidation periods. Neurobiology of Learning and Memory. 2012;98(4):321-328. doi:10.1016/j.nlm.2012.09.008.

[19] Akwa Y, Ladurelle N, Covey DF, Baulieu EE. The synthetic enantiomer of pregnenolone sulfate is very active on memory in rats and mice, even more so than its physiological neurosteroid 
counterpart: distinct mechanisms? Proceedings of the National Academy of Sciences of the United States of America. 2001;98(24):14033-14037. doi:10.1073/pnas.241503698.

[20] Péczely L, Ollmann T, László K, Kovács A, Gálosi R, Szabó A, et al. Effects of ventral pallidal D1 dopamine receptor activation on memory consolidation in morris water maze test. Behavioural Brain Research. 2014;274:211-218. doi:10.1016/j.bbr.2014.07.031.

[21] Wang W, Liu L, Jiang P, Chen C, Zhang T. Levodopa improves learning and memory ability on global cerebral ischemia-reperfusion injured rats in the Morris water maze test. Neuroscience Letters. 2017;636:233-240. doi:10.1016/j.neulet.2016.11.026.

[22] Duda W, Wesierska M, Ostaszewski P, Vales K, Nekovarova T, Stuchlik A. MK-801 and memantine act differently on shortterm memory tested with different time-intervals in the Morris water maze test. Behavioural Brain Research. 2016;311:15-23. doi:10.1016/j.bbr.2016.05.024.

[23] Taridi NM, Yahaya MF, Teoh SL, Latiff AA, Ngah WZ, Das S, et al. Tocotrienol rich fraction (TRF) supplementation protects against oxidative DNA damage and improves cognitive functions in Wistar rats. La Clinica terapeutica. 2011;162(2):93-98.

[24] Li XL, Ma RH, Ni ZJ, Thakur K, Cespedes-Acuña CL, Wang S, et al. Dioscin inhibits human endometrial carcinoma proliferation via G0/G1 cell cycle arrest and mitochondrial-dependent signaling pathway. Food and Chemical Toxicology. 2021;148:111941111941. doi:10.1016/j.fct.2020.111941.

[25] Zhang F, Ni ZJ, Ye L, Zhang YY, Thakur K, CespedesAcuña CL, et al. Asparanin A inhibits cell migration and invasion in human endometrial cancer via Ras/ERK/MAPK pathway. Food and Chemical Toxicology. 2021;150:112036112036. doi:10.1016/j.fct.2021.112036.

[26] Zhang YY, Ni ZJ, Elam E, Zhang F, Thakur K, Wang S, et al. Juglone, a novel activator of ferroptosis, induces cell death in endometrial carcinoma Ishikawa cells. Food \& Function. 2021;12(11):49474959. doi:10.1039/d1fo00790d.

[27] Yin Q, Chen H, Ma RH, Zhang YY, Liu MM, Thakur K, et al. Ginsenoside CK induces apoptosis of human cervical cancer HeLa cells by regulating autophagy and endoplasmic reticulum stress. Food \& Function. 2021;12(12):5301-5316. doi:10.1039/d1fo00348h.

[28] Gibbons TE, Pence BD, Petr G, Ossyra JM, Mach HC, Bhattacharya TK, et al. Voluntary wheel running, but not a diet containing (-)-epigallocatechin-3-gallate and $\beta$-alanine, improves learning, memory and hippocampal neurogenesis in aged mice. Behavioural Brain Research. 2014;272:131-140. doi:10.1016/j.bbr.2014.05.049.

[29] Huang WC, Chiu WC, Chuang HL, Tang DW, Lee ZM, Wei L, et al. Effect of Curcumin Supplementation on Physiological Fatigue and Physical Performance in Mice. Nutrients. 2015;7(2):905-921. doi:10.3390/nu7020905.

[30] Xi X, Guo S, Guo H, Cui X, Cao H, Xu F, et al. Antiexercise-fatigue and promotion of sexual interest activity of total flavonoids from wasps drone-pupae in male mice. Biomedicine \& Pharmacotherapy. 2018;107:254-261. doi:10.1016/j.biopha.2018.07.172.

[31] Li Y, Xin Y, Xu F, Zheng M, Xi X, Cui X, et al. Maca polysaccharides: Extraction optimization, structural features and anti-fatigue activities. International Journal of Biological Macromolecules. 2018;115:618-624. doi:10.1016/j.ijbiomac.2018.04.063.

[32] Qi B, Liu L, Zhang H, Zhou GX, Wang S, Duan XZ, et al. Anti-fatigue effects of proteins isolated from Panax quinquefolium. Journal of Ethnopharmacology. 2014;153(2):430434. doi:10.1016/j.jep.2014.02.045.

[33] Fukuda S, Nojima J, Motoki Y, Yamaguti K, Nakatomi Y, Okawa $\mathrm{N}$, et al. A potential biomarker for fatigue: Oxidative stress and anti-oxidative activity. Biological Psychology. 2016;118:88-93. doi:10.1016/j.biopsycho.2016.05.005.

[34] Coqueiro AY, Raizel R, Bonvini A, Rogero MM, Tirapegui J. Effects of glutamine and alanine supplementation on muscle fatigue parameters of rats submitted to resistance training. Nutrition. 2019;65:131-137. doi:10.1016/j.nut.2018.09.025. 